\title{
Immobilized $\mathrm{TiO}_{2}$ nanoparticles produced by flame spray for photocatalytic water remediation
}

Luca Giacomo Bettinia, *, Maria Vittoria Diamantib, Maurizio Sansotera ${ }^{\mathrm{b}}$, Maria Pia Pedeferri ${ }^{\mathrm{b}}$, Walter Navarrini $^{\mathrm{b}}$ and Paolo Milani ${ }^{\mathrm{a}}$

${ }^{\text {a }}$ CiMaINa and Physics Department, Università degli Studi di Milano, Via Celoria 16, 20133 Milano, Italy.

${ }^{\mathrm{b}}$ Department of Chemistry, Materials and Chemical Engineering “Giulio Natta”, Politecnico di Milano, Via Mancinelli 7, 20131 Milano, Italy.

\begin{abstract}
Anatase/rutile mixed-phase titanium dioxide $\left(\mathrm{TiO}_{2}\right)$ photocatalysts in the form of nanostructured powders with different primary particle size, specific surface area and rutile content were produced from the gasphase by flame spray pyrolysis (FSP) starting from an organic solution containing titanium(IV) isopropoxide as $\mathrm{Ti}$ precursor. Flame spray produced $\mathrm{TiO}_{2}$ powders were characterized by means of X-Ray diffraction, Raman spectroscopy and BET measurements. As prepared powders were mainly composed of anatase crystallites with size ranging from 7 to $15 \mathrm{~nm}$ according to the synthesis conditions. $\mathrm{TiO}_{2}$ powders were embedded in a multilayered fluoropolymeric matrix to immobilize the nanoparticles into freestanding photocatalytic membranes. The photocatalytic activity of the $\mathrm{TiO}_{2}$-embedded membranes toward the abatement of hydrosoluble organic pollutants was evaluated employing the photodegradation of rhodamine B in aqueous solution as test reaction. The photoabatement rate of best performing membranes significantly overcomes that of membranes produced by the same method and incorporating commercial P25- $\mathrm{TiO}_{2}$.

* corresponding author: (email) lucagiacomo.bettini@unimi.it, (phone) +39 0250317672, (fax) +39 0250317482
\end{abstract}

Keywords: Titanium dioxide, nanoparticles, flame spray pyrolysis, photocatalysis, water remediation 


\section{Introduction}

Degradation of organic compounds via advanced oxidation processes (AOPs) promoted by the photogenerated charges at the surface of a nanostructured photocatalyst is a promising method toward the removal of organic pollutants from water (Hermann 1999; Bahneamann 2004; Dong 2015). To date the synthesis of metal oxide semiconductors with high surface-to-volume ratio is the object of intensive research efforts directed at the production of highly active photocatalytic materials (van de Krol 2008). Titanium dioxide $\left(\mathrm{TiO}_{2}\right)$, thanks to its high photocatalytic activity, non-toxicity, chemical stability and relatively low cost, is certainly the most studied and the closest one to practical application (Hashimoto 2005). However, several issues related to the development of efficient production techniques and to the safe use of nanosized photocatalysts must still be addressed (Chen 2007; Stern 2008). The integration of photocatalytic nanoparticles into feasible reactor systems and their separation after water treatment are other key technical challenges (Chong 2010). The development of nanoparticle immobilization strategies providing both a high photocatalytic activity and a cost-effective solid-liquid separation is required towards the practicality of heterogeneous photocatalytic technology in industrial processes (Chong 2010; Wang 2014; Persico 2015).

Flame spray pyrolysis (FSP) is a well-established one-step process used to produce highly crystalline metal oxide nanoparticles (e.g. $\mathrm{TiO}_{2}, \mathrm{WO}_{3}$ and $\mathrm{ZnO}$ ) from the gas-phase by the exothermic combustion of a spray of a liquid precursor (Mädler 2002; Roth 2007; Strobel 2007; Teoh 2010). Avoidance of post-production treatments and scalability of the process are FSP intrinsic features of significant relevance toward the production of functional nanostructured oxides (Mädler 2002; Mueller 2007; Tantis 2016). Moreover, the possibility of finely tuning the structural properties (e.g. morphology, crystal phase, primary particle size and specific surface area) of FSP products simply varying synthesis conditions in the FSP reactor is a key advantage toward the optimization and engineering of nanomaterials (Teoh 2005; Bettini 2015).

FSP has been successfully used for the production of nanostructured titania-based photocatalysts with high activity toward the photo-mineralization of several organic compounds (Teoh 2007a; Bettini 2015). This photocatalytic activity has been reported to further increase when metal clusters (e.g., $\mathrm{Au}, \mathrm{Fe}$ and $\mathrm{Pt}$ ) are loaded on the $\mathrm{TiO}_{2}$ surface by directly introducing the proper metallorganic compound in the titania precursor solution (Teoh 2005; Teoh 2007b) and when the operation conditions of the FSP process are properly selected in order to optimize the $\mathrm{TiO}_{2}$ structural properties (Bettini 2015). These studies are typically based on the use of $\mathrm{TiO}_{2}$ nanoparticles in suspension or slurry-type photocatalytic reactors. However, such systems have limited industrial feasibility, on account of the low quantum efficiency reported for slurry processes and of the need for a post-treatment photocatalyst recovery stage, which may present poor efficiency, with the double drawback of dispersing nanoparticles in the environment and losing precious photocatalyst.

Recently, the development of multilayered perfluorinated coatings incorporating commercial $\mathrm{P}_{25} 5 \mathrm{TiO}_{2}$ photocatalyst and featuring high chemical stability, permeability to gases (e.g. $\mathrm{O}_{2}$ and water vapor), wettability and transparency toward UV has been reported (Persico 2015). As prepared coatings revealed 
higher photocatalytic activity than merely dispersed photocatalysts, enabling the photodegradation of hydrosoluble organic pollutants, even in turbid solution conditions, and at the same time, overcoming problems related to the photocatalyst recovery stage (Persico 2015).

Here, we present the FSP production of different $\mathrm{TiO}_{2}$ nanostructured powders and their embedding in fluoropolymeric matrices in order to produce freestanding photocatalytic membranes based on immobilized nanoparticles. The photocatalytic activity of as prepared membranes is tested by studying the degradation of rhodamine $\mathrm{B}(\mathrm{RhB})$ in aqueous solution and correlated to the structural properties of the FSP-made $\mathrm{TiO}_{2}$ photocatalysts.

\section{Experimental part}

\section{1 $\mathrm{TiO}_{2}$ synthesis and characterization}

$\mathrm{TiO}_{2}$ nanostructured powders were produced in the gas-phase by the flame spray pyrolysis (FSP) of titanium (IV) isopropoxide (TTIP, Aldrich, purity> 97\%) dissolved in xylene, employing a commercial FSP system (NPS10, Tethis S.p.A., Italy). The TTIP precursor/solvent mixture was injected by a syringe pump through a stainless steel capillary tube in a water-cooled nozzle, where it was dispersed into fine droplets by a coaxial gas flow of oxygen fed through an annular gap surrounding the capillary tube. The resulting spray was ignited by a pilot methane/oxygen flamelet (the flow rate of $\mathrm{CH}_{4}$ and $\mathrm{O}_{2}$ was 1.5 and $3 \mathrm{~L} \mathrm{~min}^{-1}$, respectively), so that the organic part of the precursor solution was combusted, while the metal was oxidized and formed particles that grew by coagulation and sintering in the flame. The precursor liquid feed flow rate was measured by a mass rate-controlled syringe pump, and all gas flows were adjusted by mass flow controllers. Different $\mathrm{TiO}_{2}$ powders were produced varying operation parameters (e.g. precursor concentration, feed flow rates of precursor and dispersion gas) as reported in Table 1. The pressure drop of the dispersion $\mathrm{O}_{2}$ gas at the nozzle tip was fixed at ca. 1.8 bar. The FSP-made powders were collected using a watercooled, stainlesssteel filter housing supporting a glass microfiber filter (Whatman GF6, $257 \mathrm{~mm}$ in diameter), with exhaust gases drawn by a vacuum pump (Busch, Seco SV/SD 1010-1040C). The filter was located downstream the FSP reactor at distance of ca. $640 \mathrm{~mm}$ from the nozzle of the burner.

X-ray powder diffraction (XRPD) patterns were recorded on a Philips PW3020 powder diffractometer, by using $\mathrm{Cu} \mathrm{K \alpha}$ radiation $(\lambda=1.54056 \AA)$. Quantitative phase analysis was made by Rietveld refinement method, using the "Quanto" software. The average anatase crystallite size was calculated according to Scherrer equation, from the integral XRD peak width calculated as the ratio between peak area and peak intensity obtained by fitting with a Gaussian function the profile of the most intense reflections at $2 \theta=25.4^{\circ}$. Raman spectra of $\mathrm{TiO}_{2}$ samples were recorded by an optical bench setup consisting of Ar ion laser emitting at $514 \mathrm{~nm}$ (Spectra Physics, beamlok series 2065-7) as excitation source, single monochromator (ActonSP2558-9N) equipped with $1200 \mathrm{~mm}^{-1}$ blaze grating, notch filter (RazorEdge ${ }^{\circledR}$ long wave pass filter LP02514RE-25), and liquid nitrogen-cooled CCD camera. Brunauer-Emmett-Teller (BET) specific surface area 
(SSA) was measured by $\mathrm{N}_{2}$ adsorption/desorption at liquid nitrogen temperature in a Micromeritics Tristar II 3020 V1.03 apparatus, after out-gassing at $300^{\circ} \mathrm{C}$ for $1 \mathrm{~h}$ under $\mathrm{N}_{2}$ stream. Scanning electron microscopy (SEM) micrographs were acquired with a Zeiss $\Sigma$ IGMA field emission instrument equipped with a Zeiss GEMINI electron optical column.

\subsection{Photocatalytic freestanding membranes}

Polymeric coatings embedding $\mathrm{TiO}_{2}$ nanoparticles were realized with AQUIVION ${ }^{\circledR}$ D83-06A (AQ) and HYFLON $^{\circledR}$ AD60 (AD); both fluoropolymers are produced by Solvay Specialty Polymers. AQ, used as received, is a melt-extruded ionomeric branched copolymer, obtained from tetrafluoroethylene (TFE) and a perfluorinated sulfonic vinyl ether (FSVE) of formula $\mathrm{F}_{2} \mathrm{C}=\mathrm{CF}-\mathrm{O}-\mathrm{CF}_{2}-\mathrm{CF}_{2}-\mathrm{SO}_{2} \mathrm{~F}$. AQ starting material is in the acidified form, in a 6\% solution of 1-propanol (40\%), 2-propanol (40\%) and water (20\%), and it has an equivalent weight of $830 \mathrm{~g} / \mathrm{eq}$, total acid capacity of $1.17-1.23$ meq g-1 and density of $0.875 \mathrm{~g} \mathrm{~cm}^{-3}$. The $\mathrm{SO}_{3} \mathrm{H}$ groups are placed as terminals of the lateral chains, conferring hydrophilicity and consequently good wettability to the photoactive coating, whereas the backbone of the polymer is highly hydrophobic due to the presence of C-F bonds (Navarrini 2008). AD is a random copolymer of TFE and 2,2,4-trifluoro-5trifluoromethoxy-1,3-dioxole (TTD), characterized by outstanding chemical stability (Persico 2013), low refractive index (equal to 1.327) and $\mathrm{T}_{\mathrm{g}}$ of $130^{\circ} \mathrm{C}$ (Avataneo 2009). $\mathrm{AD}$ was employed in solution using GALDEN ${ }^{\circledR}$ HT110 (Solvay Specialty Polymers) as solvent, a perfluoropolyether-based solvent with boiling point of $110^{\circ} \mathrm{C}$.

To prepare and deposit the photoactive coatings on glass slides a multilayer solution was adopted according to a modified technology previously described (Persico 2015). Two different perfluoropolymer solutions were employed: a $10 \mathrm{wt} \%$ solution of AD in GALDEN ${ }^{\circledR}$ HT110 and a 6 wt\% solution of AQ in a hydroalcoholic solvent (water/i-propanol/n-propanol 20:40:40) containing $0.6 \mathrm{wt} \%$ of dispersed $\mathrm{TiO}_{2}$ powders. The former acted as hydrophobic fluorinated primer as well as mechanical support, the latter as hydrophilic photoactive layer. The AD allowed the adhesion between the perfluorinated hydrophobic layer and the ionomeric hydrophilic photoactive layer by entanglement of fluorinated chains promoted by thermally curing the polymeric assembly, as described in previous work (Persico 2015).

The fine dispersion of $\mathrm{TiO}_{2}$ nanoparticles in hydroalcoholic AQ solution was obtained by ultra-sonication for $30 \mathrm{~min}$ at room temperature before its application on glass. The AQ layer with embedded $\mathrm{TiO}_{2}$ was deposited on the surface of $\mathrm{AD}$ layers and, subsequently, it was thermally cured with a specific heating program described in previous work to evaporate solvents and promote adhesion between perfluoropolymeric layers (Persico 2015). Both fluorinated polymeric AD and AQ layers are chemically stable towards the degradation effects due to $\mathrm{TiO}_{2}$ redox photocatalytic activity and to UV-Vis light under oxygen atmosphere (Persico 2013). Moreover, AQ, as ionomeric fluorinated polymer, is permeable to aqueous pollutants which can diffuse towards the activated $\mathrm{TiO}_{2}$ nanostructured powders. The coating procedure was repeated on different glass slides for each of the $\mathrm{TiO}_{2}$ powders listed in Table 1. A reference coating was produced by using 
Table 1 TTIP concentration and flow rate, dispersion $\mathrm{O}_{2}$ flow rate, molar ratio between dispersion gas and precursor $(\varphi)$, phase composition $(A=$ anatase, $R=$ rutile), anatase crystallites size $(d A)$, and specific surface area (SSA) of the $\mathrm{TiO}_{2}$ nanostructured powders produced by FSP.

\begin{tabular}{lllllllll}
\hline & TTIP & TTIP & $\mathrm{O}_{2}$ & $\varphi$ & $\mathrm{A}$ & $\mathrm{R}$ & $\mathrm{d}_{\mathrm{A}}$ & $\mathrm{SSA}$ \\
\cline { 2 - 9 } & $\mathrm{M}$ & $\mathrm{ml} \mathrm{min}{ }^{-1}$ & $\mathrm{~L} \mathrm{~min}^{-1}$ & & wt $\%$ & wt $\%$ & $\mathrm{~nm}$ & $\mathrm{~m}^{2} \mathrm{~g}^{-1}$ \\
\hline FSP-A & 0.8 & 4 & 5 & 83 & 78 & 22 & 15 & 90 \\
FSP-B & 0.45 & 4 & 5 & 127 & 82 & 18 & 12 & 113 \\
FSP-C & 0.45 & 4 & 8 & 203 & 73 & 27 & 9 & 161 \\
FSP-D & 0.45 & 1 & 5 & 500 & 88 & 11 & 7 & 249 \\
\hline
\end{tabular}

commercial AEROXIDE ${ }^{\circledR} \mathrm{P} 25-\mathrm{TiO}_{2}$ powders. After production and curing of the multilayer coating, the glass slide was immersed in distilled water to release the coating, which detached perfectly integer forming a freestanding membrane that was then cut in $2 \times 2 \mathrm{~cm}^{2}$ squares. The membrane was inserted in a Teflon ${ }^{\circledR}$ frame to prevent it from bending and winding up, leaving a $1 \mathrm{~cm}^{2}$ surface exposed.

\subsection{Photocatalytic tests}

Photocatalytic tests were performed by evaluating the degradation of rhodamine B-base (RhB - SigmaAldrich ${ }^{\circledR}$ - dye content 97\%) in aqueous solution. A detailed description of this photocatalytic mechanism has been reported elsewhere (Aarthi 2007). As prepared membranes were placed on the bottom of a $100 \mathrm{ml}$ beaker containing $15 \mathrm{ml}$ of $10^{-5} \mathrm{M} \mathrm{RhB}$ acqueous solution. Irradiation was achieved from top by using a 300 W Osram Ultra Vitalux ${ }^{\circledR}$ emitting infrared, visible, UV-A and UV-B radiation and described as simulating natural sunlight (Norros 2015). Light intensity was adjusted to produce an UVA irradiation of $10 \mathrm{~W} \mathrm{~m}^{-2}$ on the exposed membrane, as measured by a portable radiometer (Konica Minolta UM- $10^{\circledR}$, reading head centered at $365 \mathrm{~nm}$ ); at this lamp-sample distance visible range intensity was $11 \mathrm{~W} \mathrm{~m}^{-2}$ (reading head centered at $415 \mathrm{~nm}$ ). Dye absorbance was monitored in time for $6 \mathrm{~h}$ by means of an absorbance spectrophotometer as reported in previous work (Diamanti 2011), using the peak at $550 \mathrm{~nm}$ as proportional to $\mathrm{RhB}$ concentration. Further tests were conducted under Vis irradiation by introducing a $\mathrm{NaNO}_{2}$ solution as UV filter (cut-off wavelength ca. $390 \mathrm{~nm}$ (Hellma 2016)) between lamp and sample, as described elsewhere (Diamanti 2011). Irradiation intensity was checked and confirmed a zero reading at $365 \mathrm{~nm}$, while light intensity at $400 \mathrm{~nm}$ was set equivalent to full light spectrum experiments, i.e., $11 \mathrm{~W} \mathrm{~m}^{-2}$. In this case, $525 \mathrm{~nm}$ and $500 \mathrm{~nm}$ wavelengths were also monitored to evaluate the possible formation of deethylation products, which would attest a failure in the complete degradation of the molecule, and therefore a poor photocatalytic efficiency, in spite of a relevant decrease in the $550 \mathrm{~nm}$ peak (Persico 2013). Before tests, RhB absorbance was measured at different concentrations, obtaining a linear trend of absorbance vs concentration, as 


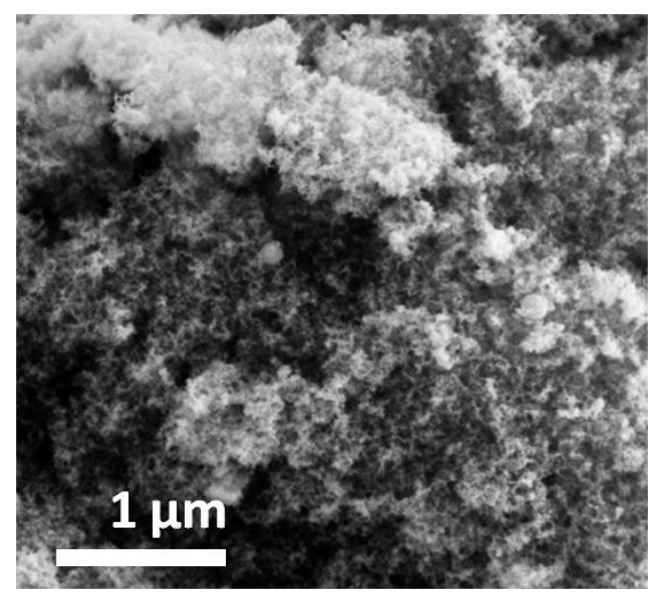

Fig. 1 SEM micrograph of FSP-made $\mathrm{TiO}_{2}$ powders.

expected by Beer Lambert equation for diluted solutions: therefore, RhB absorbance was correlated to dye concentration in solution. Data reported here already adopt this conversion.

\section{Results and Discussion}

\section{1 $\mathrm{TiO}_{2}$ production}

$\mathrm{TiO}_{2}$ nanostructured powders with different structural characteristics were produced by FSP varying the molar ratio $\varphi\left(\varphi=\mathrm{r}_{\mathrm{O} 2} / \mathrm{r}_{\mathrm{TTIP}}\right.$, where both $\mathrm{r}_{\mathrm{O} 2}$ and $\mathrm{r}_{\mathrm{TTIP}}$ are expressed in mol $\left.\mathrm{min}^{-1}\right)$ between the dispersion oxygen ( $\mathrm{r}_{2}$ ) adopted in the synthesis and the TTIP amount ( $\mathrm{r}_{\mathrm{TTIP}}$ ) fed into the flame. The control of this parameter has been recently demonstrated to allow a fine tuning of the structural properties of FSP products, as it significantly affects the synthesis conditions in terms of flame temperature, nanoparticles concentration and residence time in the flame (Bettini 2015). Four different $\mathrm{TiO}_{2}$ powders were produced at increasing $\varphi$ according to the synthesis conditions reported in Table 1. The increase in $\varphi$ produces an abundance of oxygen in the FSP reactor that decreases the TTIP droplet concentration in the flame. Due to the additional gas that has to be heated by the same amount of fuel both flame temperature and flame height are reduced (Strobel 2007; Teoh 2010; Bettini 2015). Consequently, when $\varphi$ is increased the residence time of particles in the flame and the time for crystallite growth and sintering decrease and the produced powders are characterized by smaller primary particles and higher specific surface areas (Bettini 2015).

As reported in Figure 1, where the typical scanning electron micrograph of a FSP-made $\mathrm{TiO}_{2}$ sample is shown, as prepared $\mathrm{TiO}_{2}$ powders present a nanostructured morphology that results from the aggregation and agglomeration of the primary particles produced in the flame. XRD diffractograms reported in Figure 2(a) indicate that samples have a crystalline structure consisting of a mixture of anatase and rutile phases. Analysis of XRD diffractograms points out that anatase is the predominant crystalline phase ( $>70 \mathrm{wt} \%$ in all 

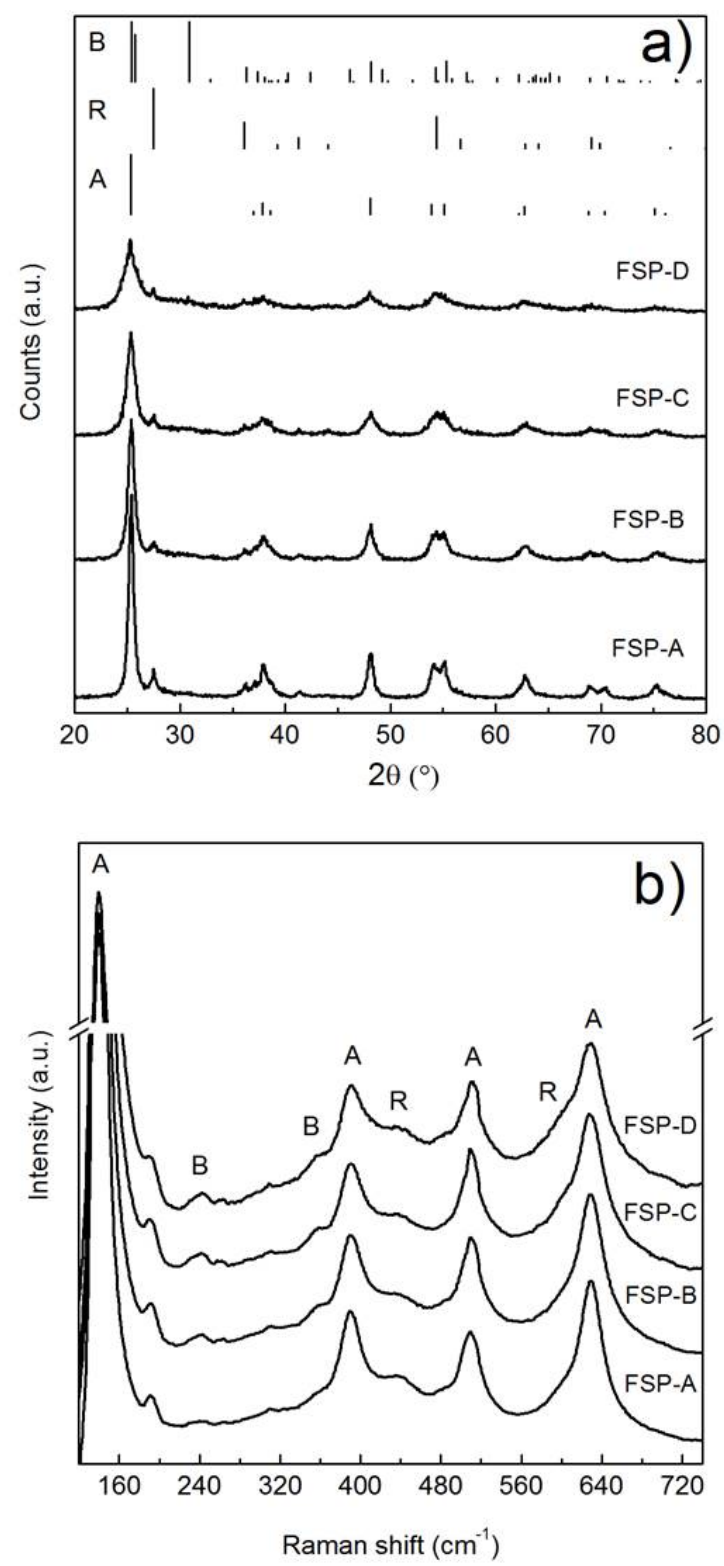

Fig. 2 a) XRD diffractograms and (b) Raman spectra of the $\mathrm{TiO}_{2}$ nanostructured powders produced by FSP. Diffraction and Raman peaks of anatase (A), rutile (R) and brookite (B) are reported.

samples) and that crystallite size decreases from 15 to $7 \mathrm{~nm}$ with the trend FSP-A>FSP-B>FSP-C $>$ FSP-D, i.e. when the abundance of oxygen in the reactor is increased (Table 1). Raman spectra of FSP-made powders (Figure 2(b)) show anatase (144, 197, 394, 513 and $635 \mathrm{~cm}^{-1}$ ) and rutile (442 and $602 \mathrm{~cm}^{-1}$ ) peaks ( $\mathrm{Li}$ Bassi 2005), confirming that as prepared $\mathrm{TiO}_{2}$ is characterized by a mixing of the two phases. Moreover, spectra show two weak Raman peaks at 246 and $366 \mathrm{~cm}^{-1}$ ascribable to the presence of brookite crystallites (Zhang 1998). As the characteristic diffraction peak of brookite at $2 \theta=31^{\circ}$ is not present in XRD diffractograms, this crystalline phase may be present in relatively small amounts, possibly below the detection limit of our XRD system (ca. 5\%). Figure 3 shows the nitrogen gas adsorption and desorption isotherms of the $\mathrm{TiO}_{2}$ samples produced by FSP. All the samples exhibit a typical type IV isotherm with a hysteretic loop in the high relative pressure range that is characteristic of mesoporous materials (Groen 


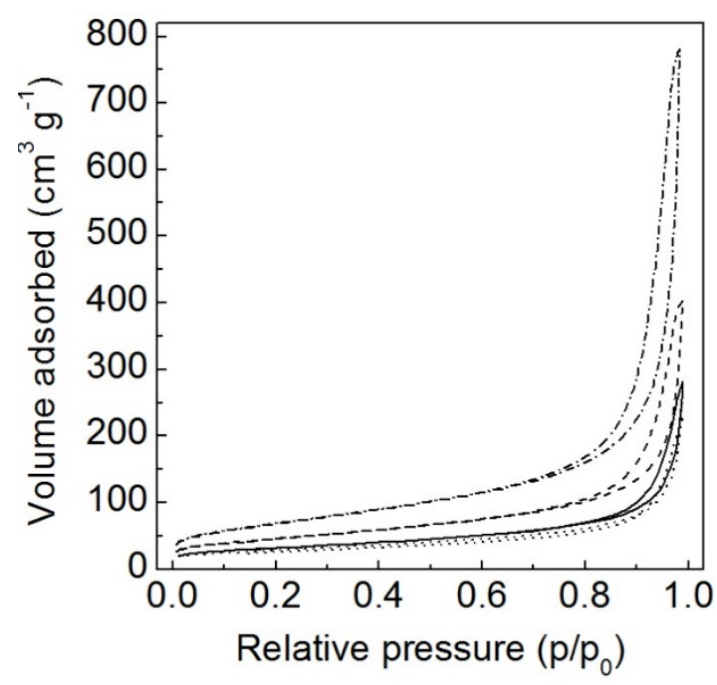

Fig. 3 Nitrogen adsorption-desorption isotherms of FSP-A (dotted line), FSP-B (solid line), FSP-C (dashed line) and FSP-D (dashed-dotted line) powders produced by flame spray pyrolysis.

2003). From these isotherms a BET specific surface area (SSA) of 90, 113, 161 and $249 \mathrm{~m}^{2} \mathrm{~g}^{-1}$ was determined for samples FSP-A, FSP-B, FSP-C and FSP-D, respectively. The evolution of the SSA of the powders, together with the concomitant evolution of their crystallite size, is strictly related to the variation of the $\varphi$ parameter that modifies the synthesis conditions thus affecting not only the primary particle formation but also their aggregation and agglomeration (Bettini 2015).

\subsection{Photocatalytic freestanding membranes}

Different freestanding photocatalytic membranes embedding the FSP-made $\mathrm{TiO}_{2}$ powders were produced and tested according to the procedure reported in the experimental section. A similar membrane incorporating a commercial $\mathrm{P} 25-\mathrm{TiO}_{2}$ was produced and tested as benchmark. $\mathrm{P} 25-\mathrm{TiO}_{2}$ is known to contain more than $70 \%$ anatase with a minor amount of rutile and to consist of primary particles with average size of 30 nm (Tahiri 1996; Ohtani 2010).

The kinetics of degradation of $\mathrm{RhB}$ under solar spectrum irradiation is reported in Figure 4(a), and is given as $\ln \left(\mathrm{C} / \mathrm{C}_{0}\right)$, with $\mathrm{C}$ concentration at the time of measurement, and $\mathrm{C}_{0}$ initial concentration. It is possible to see that the natural logarithm of RhB degradation, represented by the decrease in its concentration, follows a linear trend in time, confirming the pseudo-first order degradation kinetics often observed in literature. Membranes embedding FSP-A, FSP-B and FSP-C photocatalysts exhibit significantly higher efficiency trend compared to the one embedding $\mathrm{P} 25-\mathrm{TiO}_{2}$; membrane based on FSP-D photocatalyst shows a performances similar to the one based on commercial titania. The typical linear trend of pseudo-first order kinetics reactions is also observed in Figure 4(b), which reports the same information for tests performed under sole visible light $(\lambda>390 \mathrm{~nm})$. Under this condition only a small part of incident radiation is absorbed by the 

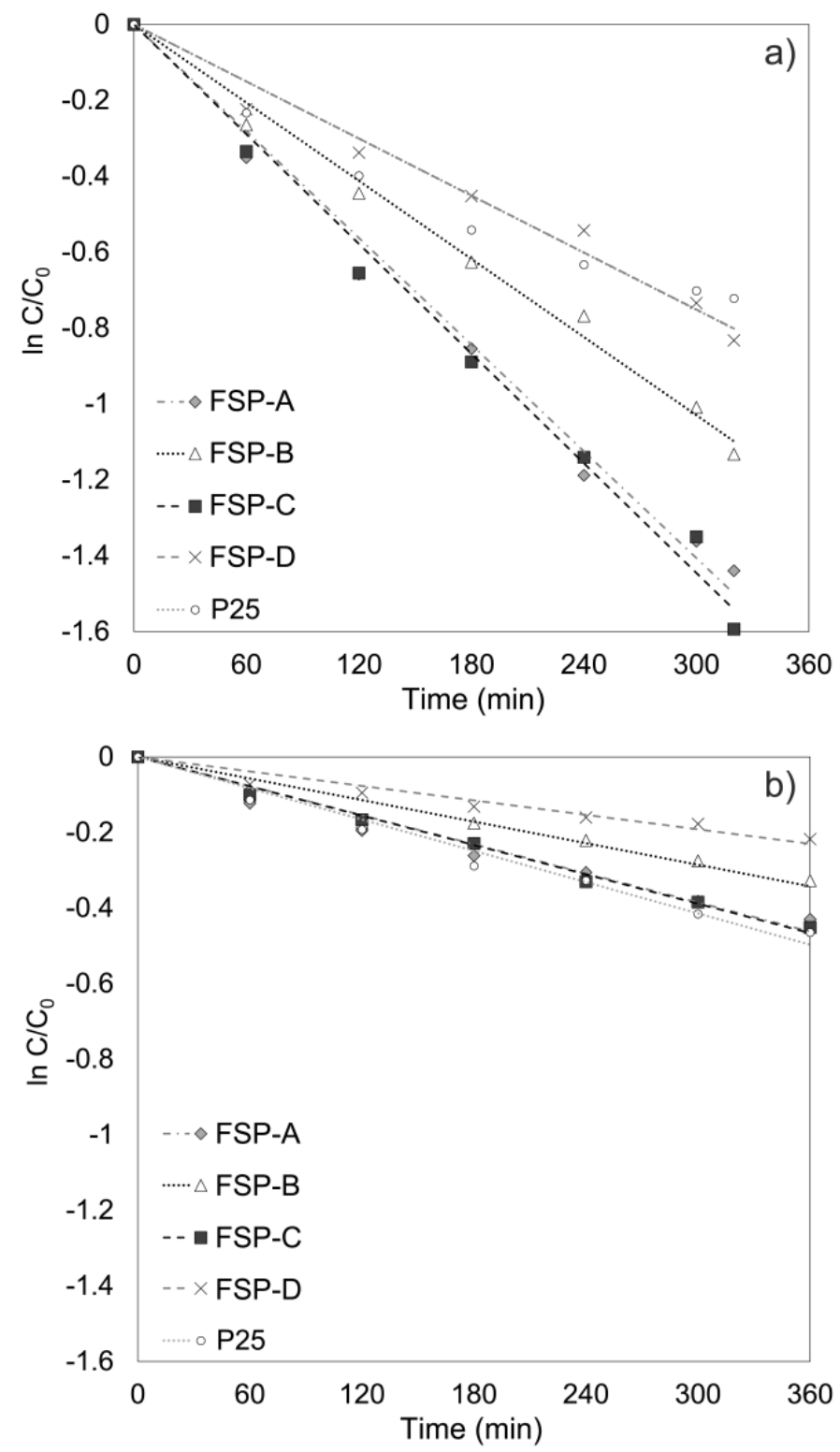

Fig. 4 Reaction kinetics for RhB degradation under (a) full solar spectrum and (b) visible light irradiation in presence of freestanding membranes containing different FSP-made $\mathrm{TiO}_{2}$ powders.

photocatalysts that, as we previously reported for $\mathrm{TiO}_{2}$ powders produced by FSP under similar operation conditions, have an absorption onset threshold located at ca. $410 \mathrm{~nm}$ (Bettini 2015), and the photoactivity of membranes is significantly lower than that exhibited under full solar spectrum. Moreover, membranes based on powders prepared by FSP show a photocatalytic activity similar (FSP-A and FSP-C) or lower (FSP-B and FSP-D) than that exhibited by the membranes based on $\mathrm{P}^{25}-\mathrm{TiO}_{2}$.

The apparent kinetic constants, $\mathrm{k}_{\mathrm{app}}$, were then calculated as the slope of $\ln \left(\mathrm{C} / \mathrm{C}_{0}\right)$ vs time, and are reported in Figure 5 where the dashed lines represent kP25, i.e., the apparent kinetic constant obtained by incorporating $\mathrm{P} 25-\mathrm{TiO}_{2}$ in the polymeric membrane. Under UV-Vis irradiation the best performing membranes based on 
FSP- $\mathrm{TiO}_{2}$, i.e. FSP-A and FSP-C, exhibit kinetic constants significantly higher than that of the membrane incorporating $\mathrm{P} 25-\mathrm{TiO}_{2}$. The increase in photocatalytic efficiency up to about $60 \%$ with respect to $\mathrm{P} 25$

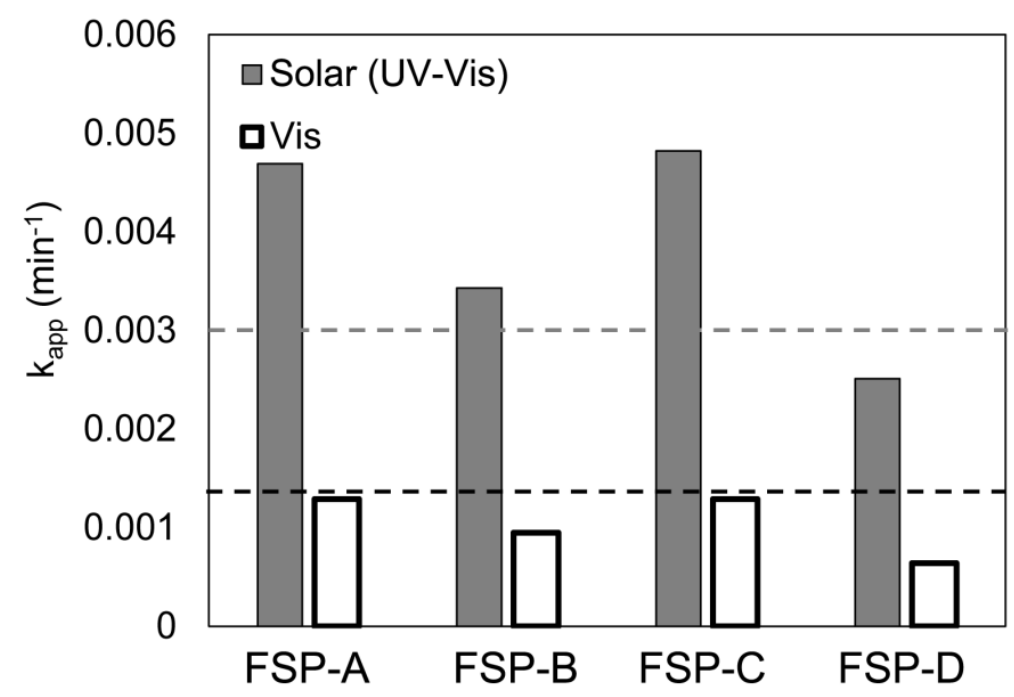

Fig. 5 Kinetic constants calculated from RhB degradation data in presence of the freestanding membranes containing different FSP-made $\mathrm{TiO}_{2}$ powders irradiated with the full solar spectrum or only with visible light. A pseudo-first order kinetics was considered. Dashed lines: $k_{a p p}$ of P25 under solar (grey) or Vis (black) irradiation.

demonstrates that highly active photocatalysts can be produced by flame spray pyrolysis and effectively immobilized in polymeric membranes. As no correlation was found with nanoparticle size and consequently with available surface area, the measured performances suggest that the ability to promote a surface reaction is, at least in the case of FSP-made samples, not univocally determined by the surface-to-volume ratio of the photocatalysts. It is known that the photocatalytic activity of $\mathrm{TiO}_{2}$ results from a synergistic effect of several physico-chemical properties and that, besides reasons of chemical nature (e.g. substrate adsorption and surface hydroxyl groups reactivity) whose characterization is beyond the scope of this work, it is strongly affected by the difference in the relative amount of anatase and rutile phases (Hurum 2003; Kho 2010; Su 2011). It is worthwhile to note that the sample showing the lowest photoactivity, i.e. FSP-D, is the one with the lowest content of rutile and that, conversely, FSP-A and FSP-C - i.e. the samples exhibiting the higher performances - present a twofold and almost threefold increased rutile content, respectively. Moreover the kinetic constants of the different samples (Figure 5) increase with the same trend that describes the increase in rutile content of the photocatalysts (Table 1), i.e. FSP-D $<$ P25 $<$ FSP-B $<$ FSP-A $<$ FSP-C, where a rutile fraction of about $15 \mathrm{wt} \%$ has been considered for $\mathrm{P}^{25}-\mathrm{TiO}_{2}$ (Ohtani 2010), suggesting that the presence of rutile favors the photodegradation of RhB. This observation is in agreement with the previously reported beneficial effect of rutile on the photocatalytic activity of mixed anatase/rutile $\mathrm{TiO}_{2}$ nanostructured materials produced by FSP (Teoh 2007a; Giannouri 2013; Bettini 2015). Indeed, the photocatalytic activity of $\mathrm{TiO}_{2}$ materials consisting in a mixture of anatase and rutile is known to be enhanced by a synergism between the 
different crystalline phase that promotes the migration of photogenerated charges thus helping the separation of electrons and holes (Hurum 2003; Kho 2010; Su 2011; Mi 2015). Beside crystalline phase, as the photocatalytic activity has been reported to be significantly affected by the crystal planes of the catalyst on which the substrate is adsorbed and degraded (D’arienzo 2011; Iglesias-Juez 2015), further efforts in the FSP synthesis of advanced photocatalysts will be aimed at the production of not only phase- and size-controlled but also shape-controlled nanoparticles.

Finally, it is interesting to observe that as prepared membranes maintain their photocatalytic activity also under sole Vis light $(\lambda>390 \mathrm{~nm})$ and that, although a decrease in the activity of approximately $60-70 \%$ is observed, the activity trend among FSP-membranes is the same under both irradiation types. Moreover by removing the UV light, the photocatalytic activity of the membranes embedding $\mathrm{FSP}$-made $\mathrm{TiO}_{2}$ nanoparticles is similar (FSP-A and FSP-C) or lower (FSP-B and FSP-D) than that of the membrane embedding $\mathrm{P}_{25}-\mathrm{TiO}_{2}$ nanoparticles. Nevertheless, these results are of interest in the frame of indoor applications of photocatalysis and demonstrate the potential of the FSP-made powders as indoor photocatalysts. Further studies will be dedicated to the optimization of powder properties (e.g. particle size, crystalline phase and band gap energy) and light irradiation to increase the photocatalytic efficiencies of FSP-TiO 2 with and without UV light.

\section{Conclusions}

Nanostructured $\mathrm{TiO}_{2}$ powders with different structural characteristics have been synthesized by flame spray pyrolysis and employed for the production of freestanding photocatalytic fluoropolymeric membranes. Photocatalytic activity of $\mathrm{TiO}_{2}$-embedding membranes was demonstrated employing the photodegradation of rhodamine B as test reaction. Under sunlight irradiation, as prepared membranes showed a significantly

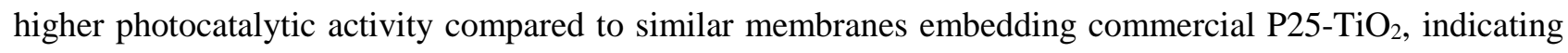
that flame spray pyrolysis is a feasible method to produce highly active nanosized photocatalysts. Although further studies are needed to correlate the structural properties of the FSP-made powders to the photoactivity of the membranes, a clear effect of the crystalline phase mixing of the $\mathrm{TiO}_{2}$ has been demonstrated. Moreover, the possibility to achieve highly efficient water purification by immobilizing the $\mathrm{TiO}_{2}$ powders in suitable polymeric membranes, avoiding any costly separation of the catalyst from the purified water, makes the reported photocatalytic system suitable for industrial employment for both sequential batch and continuous water management.

\section{Acknowledgements}

The authors thank Maria Vittoria Dozzi and Gian Luca Chiarello for assistance in BET and XRD measurements, respectively. This work was partly supported by the Italian Ministry of University and 
Research (MIUR), “National Funding for Basic Research” (FIRB RBAP11AYN) project entitled “Oxides at the nanoscale: functionalities and applications”.

\section{References}

Aarthi T, Madras G (2007) Photocatalytic Degradation of Rhodamine Dyes with Nano-TiO2. Ind Eng Chem Res 46:7-14. doi: 10.1021/ie060948n

Avataneo M, Navarrini W, De Patto U, Marchionni G (2009) Novel perfluoropolyethers containing 2, 2, 4-trifluoro-5-trifluoromethoxy-1, 3-dioxole blocks: synthesis and characterization. J Fluorine Chem 130:933-937. doi:10.1016/j.jfluchem.2009.07.007

Bahnemann D (2004) Photocatalytic water treatment: solar energy applications. Sol Energy 77: 445459. doi:10.1016/j.solener.2004.03.031

Bettini LG, Dozzi MV, Della Foglia F et al (2015) Mixed-phase nanocrystalline TiO 2 photocatalysts produced by flame spray pyrolysis. Appl Catal B-Environ 178:226-232. doi:10.1016/j.apcatb.2014.09.013

Chen X, Mao SS (2007) Titanium dioxide nanomaterials: synthesis, properties, modifications, and applications. Chem Rev 107:2891-2959. doi: 10.1021/cr0500535

Chong MN, Jin B, Chow CWK Saint C (2010) Recent developments in photocatalytic water treatment technology: a review. Water Res 44:2997-3027. doi:10.1016/j.watres.2010.02.039

D’Arienzo M, Carbajo J, Bahamonde A, Crippa M, Polizzi S, Scotti R, Wahba L, Morazzoni F. (2011) Photogenerated Defects in Shape-Controlled TiO2 Anatase Nanocrystals: A Probe To Evaluate the Role of Crystal Facets in Photocatalytic Processes. J Am Chem Soc 133: 17652-17661. doi: 10.1021/ja204838s

Diamanti MV, Ormellese M, Marin E, Lanzutti A, Mele A Pedeferri MP (2011) Anodic titanium oxide as immobilized photocatalyst in UV or visible light devices. J Hazard Mater 186: 2103-2109. doi:10.1016/j.jhazmat.2010.12.128

Dong S, Feng J, Fan M et al (2015). Recent developments in heterogeneous photocatalytic water treatment using visible light-responsive photocatalysts: a review. RCS Advances 5:14610- 14630. doi:10.1039/C4RA13734E

Giannouri M, Kalampaliki T, Todorova N, Giannakopoulou T, Boukos N, Petrakis D, Vaimakis T, Trapalis C (2013) One-Step Synthesis of TiO2/Perlite Composites by Flame Spray Pyrolysis and Their Photocatalytic Behavior. Int J Photoenergy Article ID 729460. doi: 10.1155/2013/729460

Groen JC, Peffer LAA, Pérez-Ramírez J (2003) Pore size determination in modified micro- and mesoporous materials. Pitfalls and limitations in gas adsorption data analysis. Micropor Mesopor Mat 60: 1-17. doi:10.1016/S1387-1811(03)00339-1 
Hashimoto K, Irie H, Fujishima A (2005) TiO2 photocatalysis: a historical overview and future prospects. Jpn J App Phys 44:8269. doi:10.1143/JJAP.44.8269

Hellma Analytics (2016) Calibration standards for spectrophotometers. http://www.hellmaanalytics.com/text/131/en/certified-reference-materials.html. Accessed May $13^{\text {th }} 2016$.

Herrmann JR (1999) Heterogeneous photocatalysis: fundamentals and applications to the removal of various types of aqueous pollutants. Catal Today 53:115-129. doi:10.1016/S0920-5861(99)00107-8

Hurum DC, Agrios AG, Gray KA, Rajh T, Thurnauer MC (2003) Explaining the enhanced photocatalytic activity of Degussa P25 mixed-phase TiO2 using EPR. J Phys Chem B 107:4545-4549. Doi: 10.1021/jp0273934

Iglesias-Juez A, Viñes F, Lamiel-García O, Fernández-García M, Illas F (2015) Morphology effects in photoactive ZnO nanostructures: photooxidative activity of polar surfaces. J Mater Chem A 3: 8782-8792 doi: 10.1039/C5TA01111F

Kho YK, Iwase A, Teoh WY, Mädler L, Kudo A, Amal R (2010) Photocatalytic H2 evolution over TiO2 nanoparticles. The synergistic effect of anatase and rutile. J Phys Chem C 114:2821-2829. Doi: 10.1021/jp910810r

Lee SY, Park SJ (2013) TiO2 photocatalyst for water treatment applications. J Ind Eng Chem 19:17611769. doi:10.1016/j.jiec.2013.07.012

Li Bassi A, Cattaneo A, Russo V et al (2005) Raman spectroscopy characterization of titania nanoparticles produced by flame pyrolysis: the influence of size and stoichiometry. J App Phys 98:074305. Doi: 10.1063/1.2061894

Mädler L, Kammler HK, Mueller R, Pratsinis SE (2002) Controlled synthesis of nanostructured particles by flame spray pyrolysis. J Aerosol Sci 33:369-389. doi:10.1016/S0021-8502(01)00159-8

Mi Y, Weng Y (2015) Band Alignment and Controllable Electron Migration between Rutile and Anatase TiO2. Sci Rep 5: 11482. doi: 10.1038/srep11482

Mueller R, Mädler L, Pratisinis SE (2003) Nanoparticle synthesis at high production rates by flame spray pyrolysis. Chel Eng Sci 58:1969-1976. doi:10.1016/S0009-2509(03)00022-8

Navarrini W, Scrosati B, Panero S, Ghielmi A, Sanguineti A, Geniram G (2008) Lithiated short side chain perfluorinated sulfonic ionomeric membranes: Water content and conductivity. J Power Sources 178:783-788. doi:10.1016/j.jpowsour.2007.09.110

Norros V, Karhu E, Nordén J, Vähätalo AV, Ovaskainen O (2015) Spore sensitivity to sunlight and freezing can restrict dispersal in wood-decay fungi. Ecol and Evolution 5:3312. doi: 10.1002/ece3.1589

Ohtani B, Prieto-Mahaney OO, Li D, Abe R (2010) What is Degussa (Evonik) P25? Crystalline composition analysis, reconstruction from isolated pure particles and photocatalytic activity test. $\mathrm{J}$ Photoch Photobio A 216:179-182. doi:10.1016/j.jphotochem.2010.07.024

Persico F, Sansotera M, Diamanti MV, Magagnin L, Venturini F, Navarrini W (2013) Effect of amorphous fluorinated coatings on photocatalytic properties of anodized titanium surfaces. Thin Solid Films 545:210-216. doi:10.1016/j.tsf.2013.08.004 
Persico F, Sansotera M, Bianchi CL, Cavallotti C, Navarrini W (2015) Photocatalytic activity of TiO 2embedded fluorinated transparent coating for oxidation of hydrosoluble pollutants in turbid suspensions. Appl Catal B- Environ 170:83-89. doi:10.1016/j.apcatb.2015.01.033

Roth P (2007) Particle synthesis in flames. P Combust Inst 31:1773-1788. doi:10.1016/j.proci.2006.08.118

Stern ST, McNeil SE (2008) Nanotechnology safety concerns revisited. Toxicol Sci 101:4-21. doi: 10.1093/toxsci/kfm169

Strobel R, Pratsinis SE (2007) Flame aerosol synthesis of smart nanostructured materials. J Mater Chem 17:4743-4756. Doi: 10.1039/B711652G

Su R, Bechstein R, Sø L at al (2011) How the anatase-to-rutile ratio influences the photoreactivity of TiO2. J Phys Chem C 115: 24287-24292. Doi: 10.1021/jp2086768

Tahiri H, Serpone N, van Mao RL (1996) Application of concept of relative photonic efficiencies and surface characterization of a new titania photocatalyst designed for environmental remediation. $\mathrm{J}$ Photoch Photobio A 93: 199-203. doi: 10.1016/1010-6030(95)04195-8

Tantis I, Dozzi MV, Bettini LG, Chiarello GL, Dracopoulos V, Selli E, Lianos P (2016) Highly functional titania nanoparticles produced by flame spray pyrolysis. Photoelectrochemical and solar cell applications. Appl Catal B-Environ 182:369-374. doi:10.1016/j.apcatb.2015.09.040

Teoh WY, Mädler L, Beydoun D, Pratsinis SE, Amal R (2005) Direct (one-step) synthesis of TiO2 and $\mathrm{Pt} / \mathrm{TiO} 2$ nanoparticles for photocatalytic mineralisation of sucrose. Chem Eng Sci 60:5852-5861. doi:10.1016/j.ces.2005.05.037

Teoh WY, Denny F, Amal R, Friedmann D, Mädler L, Pratsinis SE (2007) Photocatalytic mineralisation of organic compounds: a comparison of flame-made TiO2 catalysts. Top Catal 44: 489497. Doi: 10.1007/s11244-006-0096-4

Teoh WY, Amal R, Mädler L, Pratsinis SE (2007) Flame sprayed visible light-active Fe-TiO2 for photomineralisation of oxalic acid. Catal Today 120:203-213. doi:10.1016/j.cattod.2006.07.049

Teoh WY, Amal R, Mädler L (2010) Flame spray pyrolysis: an enabling technology for nanoparticles design and fabrication. Nanoscale 2:1324-1347. Doi: 10.1039/C0NR00017E

van de Krol R, Liang Y, Schoonman J (2008) Solar hydrogen production with nanostructured metal oxides. J Mater Chem 18:2311-2320. doi:10.1039/B718969A

Wang X, Zhang K, Guo X, Shen G, Xiang J (2014) Synthesis and characterization of N-doped TiO2 loaded onto activated carbon fiber with enhanced visible-light photocatalytic activity. New J Chem 38:6139-6146. Doi: 10.1039/C4NJ00962B

Zhang YH, Chan CK, Porter JF, Guo W (1998) Micro-Raman spectroscopic characterization of nanosized TiO 2 powders prepared by vapor hydrolysis. J Mater Res 13:2602-2609. Doi:10.1557/JMR.1998.0363 